\title{
Non-specificity of surfactant deficiency in neonatal respiratory disorders
}

\author{
D K JAMES, M L CHISWICK, A HARKES, M WILLIAMS, J HALLWORTH
}

\begin{abstract}
The phospholipid content of lung fluid taken from 77 babies during the first day of life was studied. Babies with hyaline membrane disease had low concentrations of the surfactant phospholipids phosphatidylcholine, phosphatidylinositol, and phosphatidylglycerol. The palmitic acid content in phosphatidylcholine was also lower than normal. Surfactant deficiency was not, however, specific for hyaline membrane disease, as similar phospholipid abnormalities were observed in babies with congenital pneumonia and transient tachypnoea of the newborn.

These findings have important clinical implications. They are relevant to research into surfactant substitution and cast doubts on the value of the antenatal phospholipid lung profile of amniotic fluid in predicting the risk of hyaline membrane disease.
\end{abstract}

\section{Introduction}

In 1959 deficiency of surfactant was shown to be the main aetiological factor in hyaline membrane disease. ${ }^{1}$ Since then information about the disease's physical and chemical properties has accumulated. ${ }^{2}{ }^{3}$ The clinical applications of this research include the antenatal prediction of the disease by measurement of the ratio of lecithin to spingomyelin ${ }^{4}$ by the lung profile, ${ }^{5-7}$ and the administration of surfactant to treat the disease. ${ }^{8-10}$

An increasing number of mothers with high risk pregnancies are now being delivered prematurely. ${ }^{11} \mathrm{~A}$ diverse range of respiratory problems occurs in prematurely born babies. For

North Western Regional Perinatal Centre, St Mary's Hospital, Manchester M13 0JH

D K JAMES, MRCOG, DCH, senior registrar in obstetrics

M L CHISWICK, MD, FRCP, consultant paediatrician

A HARKES, BSC, research biochemist

M WILLIAMS, research technician

J HALLWORTH, SRN, SCM, research nurse

Correspondence to: Mr D K James, Southmead Hospital, Westbury on Trym, Bristol BS10 5NB. example, delivery by caesarean section is associated with accumulation of fluid in the lung and transient tachypnoea of the newborn ${ }^{12}$; prolonged rupture of the membranes carries a risk of intrauterine infection and congenital pneumonia ${ }^{13}$; and persistence of the fetal circulation may result in respiratory distress in the preterm infant. ${ }^{14}$ In some babies the cause of respiratory distress is initially uncertain.

In view of these trends and the importance placed on the antenatal diagnosis of hyaline membrane disease and the use of surfactant to treat the disease we assessed the specificity of surfactant deficiency in the disease. We examined the phospholipid content of lung secretions obtained on the first day of life from babies with hyaline membrane disease, transient tachypnoea of the newborn, and congenital pneumonia.

\section{Patients and methods}

We studied 77 babies (gestational ages 27-39 weeks, birth weights 750-3900 g) who were born at this hospital. In 48 babies with respiratory distress two or more of the following signs were present at birth and persisted for several hours: cyanosis, grunting, tachypnoea, nasal flaring, and subcostal and intercostal recession. The 29 other babies had no respiratory distress and served as controls.

We collected lung fluid from endotracheal aspirates taken without lavage in the first 24 hours of life from 37 babies who were receiving endotracheal mechanical ventilation, and from gastric aspirates obtained from 40 babies within one hour after birth.

Babies were subdivided into groups according to the source of lung secretions and the clinical diagnosis made by the medical staff of the special care baby unit (table I). Two of us (DKJ and MLC) verified the diagnosis independently by reviewing the case histories and chest $x$ ray films taken in the first 24 hours of life without prior knowledge of the results of biochemical analysis of lung secretions.

\section{ENDOTRACHEAL ASPIRATES}

Babies with "normal" lungs ( $\boldsymbol{n}=9$; group 1$)$-These babies received mechanical ventilation because of drug induced respiratory depression (three), profound perinatal asphyxia (two), isolated intraventricular haemorrhage (one), apnoea caused by hypocalcaemia (one), and spondylothoracic dysplasia with diastematomyelia (one) and after operative repair of a small diaphragmatic hernia (one). These babies served as controls for babies in groups $2-4$. 
TABLE I-Summary of neonates studied, source of lung aspirates, respiratory problem, and gestational age

\begin{tabular}{|c|c|c|c|c|}
\hline Group & $\begin{array}{l}\text { Source of } \\
\text { aspirate }\end{array}$ & Respiratory problem & $\begin{array}{c}\text { No of babies } \\
\text { (and } \\
\text { aspirates) }\end{array}$ & $\begin{array}{c}\text { Median (range) } \\
\text { gestational age } \\
\text { (weeks) }\end{array}$ \\
\hline 1 & Endotracheal & Normal lungs (controls for & 9 & $36 \quad(27-39)$ \\
\hline 2 & Endotracheal & $\begin{array}{l}\text { Non-lethal hyaline } \\
\text { membrane disease }\end{array}$ & 9 & $(27-36)$ \\
\hline 3 & Endotracheal & Lethal hyaline membrane & 10 & $(25-34)$ \\
\hline $\begin{array}{l}4 \\
5\end{array}$ & $\begin{array}{l}\text { Endotracheal } \\
\text { Gastric }\end{array}$ & $\begin{array}{l}\text { Congenital pneumonia } \\
\text { Normal lungs (controls for } \\
\text { groups } 6 \text { and } 7 \text { ) }\end{array}$ & $\begin{array}{r}9 \\
20\end{array}$ & $\begin{array}{l}27 \quad(25-32) \\
34.5(30-37)\end{array}$ \\
\hline 6 & Gastric & $\begin{array}{l}\text { Hyaline membrane disease } \\
\text { of varying severity }\end{array}$ & 11 & $30 \cdot 0(26-35)$ \\
\hline 7 & Gastric & $\begin{array}{l}\text { Transient tachypnoea of } \\
\text { the newborn }\end{array}$ & 9 & $33.0(29-39)$ \\
\hline
\end{tabular}

Obstetric details may be obtained from DKJ.

Babies with non-lethal hyaline membrane disease $(n=9 ;$ group 2$)$ Endotracheal aspirates were obtained from the nine babies with hyaline membrane disease who survived. The disease was diagnosed by the presence of respiratory distress and the characteristic chest $x$ ray appearances (granular lung fields, air bronchograms, and poorly inflated lungs).

Babies with lethal hyaline membrane disease ( $n=10$; group 3$)$-These babies had more severe disease as judged by ventilation requirements and the incidence of pneumothorax and intraventricular haemorrhage (table II).

TABLE II-Ventilation characteristics during first 24 hours and complications in babies with hyaline membrane disease

\begin{tabular}{lcc}
\hline & $\begin{array}{c}\text { Survived } \\
\text { (group 2) }\end{array}$ & $\begin{array}{c}\text { Died } \\
\text { (group 3) }\end{array}$ \\
\hline No of babies & 9 & 10 \\
Mean (SD) peak ventilatory pressure (mm Hg)† & $22 \cdot 7(4 \cdot 6)$ & $30 \cdot 3(7 \cdot 8)^{*}$ \\
Mean (SD) inspired oxygen concentration $(0) \dagger$ & $64 \cdot 6(9 \cdot 0)$ & $85 \cdot 2(16 \cdot 8)^{* *}$ \\
No with pneumothorax & 4 & 6 \\
No with intraventricular haemorrhage & 4 & 8 \\
\hline
\end{tabular}

Significance of difference (Student's $t$ test) :* $\mathrm{p}<0.01,{ }^{* *} \mathrm{p}<0.002$.

$\ddagger$ Diagnosed either by ultrasound scan or at postmortem examination.

Babies with congenital pneumonia ( $n=9$; group 4)-Congenital pneumonia was diagnosed by the presence of respiratory distress with the characteristic appearances of patchy consolidation in the chest $x$ ray film. All nine babies had abnormalities of the peripheral white cell count in the first 72 hours of life indicative of infection. ${ }^{15}$ In eight babies organisms were cultured from gastric or endotracheal aspirates taken on the first day (Streptococcus viridans (three), Staphylococcus epidermidis (two), non-haemolytic streptococcus (two), Klebsiella enterobacter (one), Pseudomonas aeruginosa (one), and Bacteroides fragilis (one)).

\section{GASTRIC ASPIRATES}

Babies with "normal" lungs ( $n=20$; group 5 )-The gastric aspirates taken within an hour after birth from the 20 babies who did not develop respiratory problems served as controls for groups 6 and 7 .

Babies with hyaline membrane disease of varied severity $(n=11$; group 6)-Seven babies required mechanical ventilation for severe hyaline membrane disease, of whom five survived. The remaining four infants who survived had mild disease, which required only oxygen treatment.

Babies with transient tachypnoea of the newborn $(n=9)$; group 7$)$ The condition was diagnosed by the presence of respiratory distress and chest $x$ ray appearances of diffuse vascular streakiness of the lung fields radiating from the hili, pleural effusions in the interlobar fissures and costophrenic angles, and air trapping in well inflated lungs. Six babies required no more than a $30 \%$ ambient oxygen concentration and could be nursed in air by the third day. Three babies required an ambient oxygen concentration of up to $40 \%$ and could be nursed in air by the fifth day.

\section{COLLECTION AND STORAGE OF SPECIMENS}

The endotracheal aspirates were collected with a sterile endotracheal suction catheter attached to a low pressure vacuum source with a water trap interposed. The gastric aspirates were collected via a nasogastric tube using a similar technique. The water trap and suction tubing were labelled, placed in a plastic bag, and stored at $-20^{\circ} \mathrm{C}$ until biochemical assay was carried out.

\section{ANALYSIS OF PHOSPHOLIPIDS}

Before analysis the contents of each plastic bag were thawed at room temperature. The secretions were removed from the water trap and suction catheter by irrigation with $1 \mathrm{ml}$ physiological saline followed by $1 \mathrm{ml}$ methanol. Lipids were extracted with methanol and chloroform. ${ }^{16}$

One half of the lipid extract was used for quantitative assay of phospholipids by spectrophotometric analysis of phosphorus content. The other half was used to measure the fatty acid content of phosphatidylcholine (lecithin) by conversion to methyl esters and assay by gas liquid chromatography, as described elsewhere. ${ }^{1718}$ For analysis of endotracheal aspirates gas liquid chromatography was run isothermally at $165^{\circ} \mathrm{C}$; for the gastric aspirates a two stage programme was used $\left(16\right.$ minutes at $165^{\circ} \mathrm{C}$, then increasing by $2.5^{\circ} \mathrm{C}$ per minute to $190^{\circ} \mathrm{C}$ and remaining at $190^{\circ} \mathrm{C}$ for eight minutes).

\section{Results}

Hyaline membrane disease (table III)-Both endotracheal aspirates (groups 2 and 3 ) and gastric aspirates (group 6) taken from babies with hyaline membrane disease had lower levels of phosphatidylcholine, phosphatidylinositol, and phosphatidylglycerol compared with babies in the respective control groups (groups 1 and 5). This was true whether the three phospholipids were expressed as a proportion of total phospholipids or as a ratio to sphingomyelin (table III). There

TABLE III-Phospholipids in babies with hyaline membrane disease (HMD) and controls (figures are medians (and ranges))

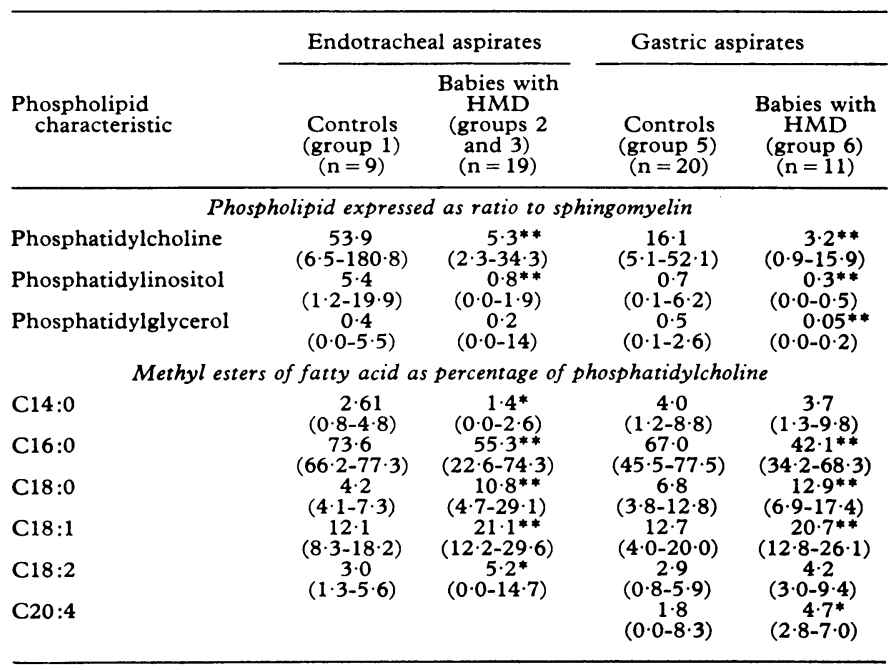

Significance of difference from controls (Mann-Whitney $U$ test): ${ }^{*} p<0.05$ $* * 0<001$.

was significantly less methyl palmitate $(\mathrm{C} 16: 0)$ and methyl myristate $(\mathrm{C} 14: 0)$ in phosphatidylcholine from aspirates taken from babies with hyaline membrane disease compared with controls, but there were compensatory increases in the relative proportions of methyl stearate (C18:0), methyl oleate (C18:1), and methyl linoleate (C18:2). Endotracheal aspirates taken from babies with lethal hyaline membrane disease (group 3) had lower levels of phosphatidylcholine, phosphatidylinositol, and phosphatidylglycerol and less methyl palmitate in the phosphatidylcholine compared with aspirates from babies with nonlethal hyaline membrane disease (group 2). None of these differences, however, were significant. 
Congenital pneumonia and transient tachypnoea of the newborn (table IV)-Babies with congenital pneumonia (group 4; endotracheal aspirates) and with transient tachypnoea of the newborn (group 7 ; gastric aspirates) showed abnormalities of phospholipid composition similar to those found in the babies with hyaline membrane disease when compared with their controls (groups 1 and 5, respectively) that is, lower levels of phosphatidylcholine, phosphatidylinositol, and phosphatidylglycerol and a lower palmitic acid content in the phosphatidylcholine.

TABLE IV-Phospholipids in babies with congenital pneumonia (endotracheal aspirates) and transient tachypnoea of the newborn (gastric aspirates) and their controls (figures are medians (and ranges))

\begin{tabular}{|c|c|c|c|c|}
\hline \multirow{2}{*}{$\begin{array}{l}\text { Phospholipid } \\
\text { characteristic }\end{array}$} & \multicolumn{2}{|c|}{ Congenital pneumonia } & \multicolumn{2}{|c|}{$\begin{array}{l}\text { Transient tachypnoea } \\
\text { of the newborn }\end{array}$} \\
\hline & $\begin{array}{l}\text { Controls } \\
(\text { group 1) } \\
(\mathrm{n}=9)\end{array}$ & $\begin{array}{c}\text { Patients } \\
\text { (group 4) } \\
(n=9)\end{array}$ & $\begin{array}{c}\text { Controls } \\
(\text { group 5) } \\
(\mathrm{n}=20)\end{array}$ & $\begin{array}{c}\text { Patients } \\
\text { (group 7) } \\
(\mathrm{n}=9)\end{array}$ \\
\hline \multicolumn{5}{|c|}{ Phospholipid expressed as ratio to sphingomyelin } \\
\hline $\begin{array}{l}\text { Phosphatidylcholine } \\
\text { Phosphatidylinositol } \\
\text { Phosphatidylglycerol }\end{array}$ & $\begin{array}{c}53 \cdot 9 \\
(6 \cdot 5-180 \cdot 8) \\
5 \cdot 4 \\
(1 \cdot 2-19 \cdot 9) \\
0 \cdot 4 \\
(0 \cdot 0-5 \cdot 5)\end{array}$ & $\begin{array}{c}22 \cdot 4^{*} \\
(2 \cdot 6-133 \cdot 6) \\
1 \cdot 1^{*} \\
(0 \cdot 4-15 \cdot 9) \\
0 \cdot 3 \\
(0 \cdot 1-1 \cdot 8)\end{array}$ & $\begin{array}{c}16 \cdot 1 \\
(5 \cdot 1-52 \cdot 1) \\
0 \cdot 7 \\
(0 \cdot 1-6 \cdot 2) \\
0 \cdot 5 \\
(0 \cdot 1-2 \cdot 6)\end{array}$ & $\begin{array}{c}7 \cdot 0 * * * \\
(1 \cdot 7-23 \cdot 5) \\
0 \cdot 4 \\
(0 \cdot 2-1 \cdot 8) \\
0 \cdot 03^{* * *} \\
(0 \cdot 0-0 \cdot 3)\end{array}$ \\
\hline \multicolumn{5}{|c|}{ Methyl esters of fatty acid as percentage of phosphatidylcholine } \\
\hline $\begin{array}{l}\mathrm{C} 14: 0 \\
\mathrm{C} 16: 0\end{array}$ & $\begin{array}{c}2 \cdot 6 \\
(0 \cdot 8-4 \cdot 8) \\
73 \cdot 6\end{array}$ & $\begin{array}{c}3 \cdot 0 \\
(0.4-6 \cdot 0) \\
61 \cdot 1 * *\end{array}$ & $\begin{array}{c}4 \cdot 0 \\
(1 \cdot 2-8 \cdot 8) \\
67 \cdot 0\end{array}$ & $\begin{array}{c}4 \cdot 3 \\
(1 \cdot 7-10 \cdot 6) \\
55 \cdot 2 * * *\end{array}$ \\
\hline $\mathrm{C} 18: 0$ & $\begin{array}{c}(66 \cdot 2-77 \cdot 3) \\
4 \cdot 2 \\
(4 \cdot 1-7 \cdot 3)\end{array}$ & $\begin{array}{c}(58 \cdot 2-64 \cdot 9) \\
6 \cdot 2 \\
(3 \cdot 8-9 \cdot 4)\end{array}$ & $\begin{array}{c}(45 \cdot 5-77 \cdot 5) \\
6 \cdot 8 \\
(3 \cdot 8-12 \cdot 8)\end{array}$ & $\begin{array}{c}(47 \cdot 1-71 \cdot 0) \\
7 \cdot 7 \\
(6 \cdot 1-11 \cdot 8)\end{array}$ \\
\hline $\mathrm{C} 18: 1$ & $(8 \cdot 3 \cdot 18 \cdot 2)$ & $\begin{array}{r}16 \cdot 6^{* * *} \\
(13 \cdot 0-21 \cdot 8)\end{array}$ & $(4.0-20.0)$ & $\begin{array}{c}14 \cdot 8 \\
(9 \cdot 4-22 \cdot 3\end{array}$ \\
\hline $\mathrm{C} 18: 2$ & $\begin{array}{c}3 \cdot 0 \\
(1 \cdot 3-5 \cdot 6)\end{array}$ & $\begin{array}{c}3 \cdot 8 \\
(2 \cdot 0-7 \cdot 4)\end{array}$ & $\begin{array}{c}2.9 \\
(0.8-5.9)\end{array}$ & $\begin{array}{c}5 \cdot 8 \\
(0.0-7 \cdot 2)\end{array}$ \\
\hline $\mathrm{C} 20: 4$ & & & $\begin{array}{c}1 \cdot 8 \\
(0 \cdot 0-8 \cdot 3)\end{array}$ & $\begin{array}{r}4 \cdot 3^{* *} \\
(1 \cdot 1-9 \cdot 5)\end{array}$ \\
\hline
\end{tabular}
Significance of difference from controls (Mann-Whitney $U$ test): ${ }^{*} p<0.07$
$* * p<0.05, * * * p<0.005$.

\section{Discussion}

For many years phosphatidylcholine has been recognised as the most important surfactant phospholipid. ${ }^{4}$ More recently, the important roles of the "minor" phospholipids, phosphatidylinositol and phosphatidylglycerol, have been shown. ${ }^{519} 20$ In terms of phospholipids, it is now thought that two types of surfactant are produced by the fetus. The "early" type comprises phosphatidylcholine and phosphatidylinositol and is normally found at 34-36 weeks. The "late" type comprises these two plus phosphatidylglycerol and is found in term babies (37 weeks or more). ${ }^{21}$ The lower concentrations of these three phospholipids in lung secretions from babies with hyaline membrane disease (groups 2, 3,6) are thus in keeping with present knowledge.

The lower palmitic acid content of phosphatidylcholine from babies with hyaline membrane disease is also consistent with findings of other workers. ${ }^{22}$ In vitro studies show that dipalmitoylphosphatidylcholine lowers surface tension more effectively than unsaturated phosphatidylcholine. ${ }^{23}$

We made the unexpected observation that babies with congenital pneumonia and transient tachypnoea of the newborn had similar abnormalities of surfactant phospholipids to babies with hyaline membrane disease. Both conditions were diagnosed on the basis of strictly defined clinical and radiological criteria and without prior knowledge of the biochemical results.

One explanation for our findings is that two or more respiratory problems might coexist in a neonate. From necropsy studies we know that both histological and bacteriological evidence of infection may be found in lungs with obvious hyaline membranes, showing that congenital pneumonia and hyaline membrane disease may coexist. This might explain why babies with congenital pneumonia (group 4) have biochemical evidence of surfactant deficiency. Alternatively, surfactant abnormalities in babies with congenital pneumonia may be secondary: infection might result in alveolar epithelial damage and thus impaired production of surfactant. Indeed, in hyaline membrane disease itself the production of surfactant is further diminished, owing to alveolar epithelial damage as the disease progresses, by the secondary effects of accumulation of fluid, pulmonary hypoperfusion, and hypertension. ${ }^{24}$

Surfactant deficiency in transient tachypnoea of the newborn may also be a secondary phenomenon, with accumulation of fluid causing alveolar epithelial damage. Possibly, however, the surfactant abnormality is a primary problem. Staub showed that lack of surfactant increases alveolar surface tension and thereby causes alveolar flooding and pulmonary oedema. ${ }^{25}$ Perhaps there is a group of babies in whom the principal manifestation of surfactant deficiency is accumulation of fluid rather than atelectasis and we diagnose these babies as having transient tachypnoea of the newborn rather than hyaline membrane disease. Atelectasis might not be the dominant feature in such babies because their lungs have achieved a critical level of morphological maturity. Alternatively, a high interstitial fluid content per se might prevent alveolar collapse; even in hyaline membrane disease areas of accumulation of fluid with minimal atelectasis may be found. ${ }^{24}$

What are the practical implications of our study? Firstly, our results are relevant to research in surfactant replacement treatment. To assess the efficacy of such treatment the risk of babies developing hyaline membrane disease (if left untreated) must be predicted from pretreatment gastric or pharyngeal secretions. ${ }^{826}$ Our study suggests that prediction of discrete hyaline membrane disease by biochemical analysis of gastric or pharyngeal secretions is not reliable. Secondly, the results have implications for obstetricians who wish to predict hyaline membrane disease antenatally by examining the phospholipid lung profile in amniotic fluid, which is apparently more accurate than the ratio of lecithin to sphingomyelin alone. ${ }^{5-7}$ Our findings suggest that antenatal assay of phospholipids predicts not only hyaline membrane disease but also transient tachypnoea of the newborn, (as we and others have observed previously. ${ }^{6}{ }^{27}$ ). In view of the potential difference in severity between these two conditions our work casts doubts on the value of antenatal lung profiles. Finally, there are practical implications for those carrying out perinatal audit. Precise clinical and radiological differentiation of neonatal respiratory disorders is difficult. Our results show that biochemical markers do not resolve this problem.

We are grateful to the University of Manchester, the William Walter Will Trust, the North Western Regional Health Authority, and Birthright for financial help. We thank Mrs Patricia Taylor and Mrs Claire Saunders for secretarial help.

\section{References}

1 Avery ME, Mead J. Surface properties in relation to atelectasis and hyaline membrane disease. Am F Dis Child 1959;97:517-23.

2 Morley CJ, Bangham AD, Thorburn GD, Johnson B, Jenkins G, Parry D. The biochemistry and physiology of pulmonary surfactant. In: Anderson, A, Beard R, Brudenell JM, Dunn P, eds. Preterm labour. London: Royal College of Obstetricians and Gynaecologists, 1977:261-72. (Proceedings of the 5th study group of the Royal College of Obstetricians and Gynaecologists.)

${ }^{3}$ Farrell PM, Hamosh M. The biochemistry of fetal lung development. Clin Perinatol 1978;5:197-229.

4 Gluck L, Kulovich MV, Borer RC, Brenner PH, Anderson GG, Spellacy WN. Diagnosis of the respiratory distress syndrome by amniocentesis. Am $\mathcal{F}$ Obstet Gynecol 1971;109:440-5.

${ }^{5}$ Kulovich MV, Hallman MB, Gluck L. The lung profile. Am $\mathcal{F}$ Obstet Gynecol 1979;139:57-70.

${ }^{6}$ Hallman M, Teramo K. Measurement of the lecithin/spingomyelin ratio and phosphatidylglycerol in amniotic fluid: an accurate method for the assessment of fetal lung maturity. Br $\mathcal{F}$ Obstet Gynaecol 1981;88:806-13.

7 Whittle MJ, Wilson AI, Whitfield CR, Paton RD, Logan RW. Amniotic fluid phosphatidylglycerol and the lecithin/spingomyelin ratio in the assessment of fetal lung maturity. Br $\mathcal{F}$ Obstet Gynaecol 1982;89:727-32.

8 Fujiwara T, Cluda S, Watabe Y, Maeta H, Morita T, Abe T. Artificial surfactant therapy in hyaline membrane disease. Lancet 1980;i:55-9.

Morley CJ, Bangham AD, Miller N, Davis JA. Dry artificial lung surfactant and its effect on very premature babies. Lancet $1981 ; \mathrm{i}: 64-8$. 
10 Enhorning E. Hyaline membrane disease and artificial surfactant. In: Chiswick ML, ed. Recent advances in perinatal medicine. Edinburgh: Churchill Livingstone, 1983:191.

$"$ James DK, Tindall VR, Richardson T. Is the lecithin/spingomyelin ratio outdated? Br F Obstet Gynaecol 1983;90:995-1000.

12 Avery ME, Gatewood OB, Brumley G. Transient tachypnea of the newborn. Possible delayed resorption of fluid at birth. Am $\mathcal{F}$ Dis Child 1966; 111:380-5.

13 Mead P. Premature rupture of the membranes. In: Chiswick ML, ed Recent advances in perinatal medicine. Edinburgh: Churchill Livingstone 1983:77.

14 Halliday HL, McClure G, Reid MMcC. Transient tachypnoea of the newborn: two distinct clinical entities? Arch Dis Child 1981;56:322-5.

15 Xanthou M. Leucocyte blood picture in healthy full-term and premature babies during neonatal period. Arch Dis Child 1970;45:242-9.

${ }^{16}$ Folch J, Lees M, Sloane-Stanley GH. A simple method for isolation and purification of total lipids from animal tissues. F Biol Chem 1957;226: 497-509.

17 James DK, Harkes A, Williams M, et al. Amniotic fluid phosphatidylglycerol and prediction of fetal lung maturity in diabetic pregnancies. Fournal of Obstetrics and Gynaecology 1984;4:166-9.

18 James DK, Chiswick ML, Harkes A, Williams M, Tindall VR. Maternal diabetes and neonatal respiratory distress. 1. Maturation of fetal surfactant. Br $\mathcal{f}$ Obstet Gynaecol (in press).
${ }^{19}$ Hallman M, Kulovich MV, Kirkpatrick E, Sugarman RG, Gluck L. Phosphatidylinositol (PI) and phosphatidylglycerol (PG) in amniotic fluid; indices of lung maturity. Am f Obstet Gynecol 1976;125:613-7.

20 Obladen M, Merritt TA, Gluck L. Acceleration of pulmonary surfactant maturation in stressed pregnancies. Am $\mathcal{F}$ (Obstet Gynecol 1979;135: 1079-85.

21 Gluck L. Fetal lung development. Mead Fohnson Symp Perinat Dev Med 1980;14:40-9.

${ }^{22}$ Shelley SA, Kovacevic M, Piciga JE, Balis JU. Sequential changes of surfactant phosphatidylcholine in hyaline membrane disease of the newborn. N Engl f Med 1979;300:112-6.

${ }^{23}$ King RJ. Pulmonary surface-active material; basic concepts. Mead fohnson Symp Perinat Dev Med 1980;14:3-11.

24 Strang LB. Heterogeneity of pathogenic mechanisms in hyaline membrane disease. Mead Fohnson Symp Perinat Dev Med 1980;14:52-8.

${ }^{25}$ Staub NC. Effects of alveolar surface tension on the pulmonary vascular bed. Fpn Heart 7 1966;7:386.

${ }^{26}$ James DK, Harkes A. Dry artificial lung surfactant in prematurity. Lancet $1981 ; \mathrm{i}: 555$.

27 James DK, Chiswick ML, Harkes A, Williams N, Tindall VR. Maternal diabetes and neonatal respiratory distress. II. Prediction of fetal lung maturity. Br $\mathrm{F}$ Obstet Gynaecol (in press).

(Accepted 1 March 1984)

\title{
Neuropathy and fatal hepatitis in a patient receiving amiodarone
}

\author{
P K LIM, P N TREWBY, G C A STOREY, D W HOLT
}

\begin{abstract}
Muscle weakness, neuropathy, and transient rises in hepatic enzyme activity have been reported with the use of the antiarrhythmic agent amiodarone. A 68 year old teetotaller with normal liver function was given amiodarone for resistant supraventricular arrhythmias. He presented 19 months later with vomiting, muscle weakness and wasting, sensory neuropathy, and hepatomegaly. Liver biopsy showed fibrosis and the presence of hyaline. The amiodarone was withdrawn. Three months later he developed ascites. Oesophageal varices were found and he later died. The liver showed micronodular cirrhosis.

The large volume of distribution and long half life of amiodarone may explain the persistence of toxicity, which may have been aggravated by simultaneously administered doxepin in this case. Amiodarone should be withdrawn if abnormal liver function or neuropathy develops.
\end{abstract}

\section{Introduction}

Transient rises in hepatic enzyme activity have been reported in $40 \%$ of patients receiving the antiarrhythmic agent amiodarone. ${ }^{1}$ More severe liver damage has been mentioned but no details given. ${ }^{2}$ Muscle weakness and neuropathy have also been

Darlington Memorial Hospital, Darlington DL3 6HX

P K LIM, MB, senior house officer

P N TREWBY, MD, MRCP, consultant physician

Poisons Unit, Guy's Hospital, London SE1 9RT

G C A STOREY, BSC, biochemist

D W HOLT, BSC, PHD, principal biochemist

Correspondence to: Dr P N Trewby. described. ${ }^{3}$ We describe a patient with irreversible neuropathy and severe hepatitis progressing to cirrhosis, which was apparently caused by amiodarone.

\section{Case report}

In February 1981 the patient, aged 68, was given amiodarone, $400 \mathrm{mg}$ daily, for resistant supraventricular arrhythmias attributed to underlying ischaemic heart disease. Liver function was normal. The dose was increased to $600 \mathrm{mg}$ daily in June to control the arrhythmia. In October 1982 the patient presented with vomiting and muscle weakness of one month's duration. Examination showed striking muscle wasting and distal sensory polyneuropathy. The liver was enlarged and finger clubbing was present.

Other medication comprised digoxin (started November 1976), doxepin (August 1980), and bumetanide (June 1981). The patient was a lifelong teetotaller.

Results of investigations were: serum bilirubin concentration 28 $\mu \mathrm{mol} / 1(163.7 \mathrm{mg} / 100 \mathrm{ml})$; alkaline phosphatase activity $854 \mathrm{IU} / 1$; serum aspartate aminotransferase activity $142 \mathrm{IU} / 1$; serum albumin concentration $29 \mathrm{~g} / \mathrm{l}$; and negative results to tests for hepatitis B surface antigen, hepatitis A antibody, Venereal Disease Research Laboratory test, and autoantibodies; urinary porphyrins were not detected. Plasma concentrations of amiodarone and desethyl amiodarone were 5.0 and $4.0 \mathrm{mg} / 1$ respectively.

Needle liver biopsy showed periportal and centrilobular fibrosis with a moderate infiltrate of lymphocytes and plasma cells. The liver cells were swollen and some contained hyaline material resembling Mallory's hyaline. Amiodarone was withdrawn and there was a prompt fall in liver enzyme activity and a temporary clinical improvement (figure). Other medication remained unchanged.

Three months later he developed ascites and a barium swallow examination showed oesophageal varices. The patient died from liver failure five months after stopping amiodarone.

A postmortem liver biopsy showed established micronodular cirrhosis. Electron microscopy showed scattered multilamellar bodies, some with a distinct membrane suggesting a lysosomal origin.

Nerve conduction studies and electromyography performed shortly after admission suggested sensorimotor polyneuropathy of axonal type. Histological findings from the right quadriceps were also consistent with patchy denervation. 